\title{
Hypnotic accumulation and hangover in elderly inpatients: a controlled double-blind study of temazepam and nitrazepam
}

\author{
PETER J COOK, ANTHONY HUGGETT, RUTH GRAHAM-POLE, IMOGEN T SAVAGE, \\ IAN M JAMES
}

\begin{abstract}
The hypnotic and residual sedative effects of the first and seventh of seven regular night-time doses of nitrazepam $5 \mathrm{mg}$, temazepam $20 \mathrm{mg}$, and placebo were studied in 58 elderly inpatients. Plasma temazepam and nitrazepam concentrations rose by about $50 \%$ and $113 \%$ respectively between the mornings of day 1 and day 7. Patients reported sleeping well more often after the first dose of either hypnotic $(\mathbf{p}<0.05)$, but there was no difference after the seventh dose. Reaction time was unchanged on the morning after the first dose but was significantly prolonged after the seventh dose of both hypnotics $(p<0.01)$. The time taken to eliminate the letter $E$ from a page of prose tended to be prolonged after the first dose of both drugs (temazepam $v$ placebo, $p<0.05$; nitrazepam $v$ placebo, not significant) and was further prolonged on the morning after the seventh dose of nitrazepam (nitrazepam $v$ placebo, $\mathbf{p}<0.05$ ).

Thus plasma accumulation of the drug was associated with a deterioration in daytime performance. This change in performance did not correlate with age, cerebral blood flow, or plasma concentration, but patients of low intelligence tended to be more severely affected.
\end{abstract}

\section{Introduction}

Temazepam (3-hydroxydiazepam) is a normal metabolite of diazepam that has a fairly short elimination half life of about eight hours in healthy young subjects. ${ }^{12}$ The rate of elimination is only slightly prolonged in healthy elderly subjects but may exceed 16 hours in elderly inpatients. ${ }^{3}$ Nitrazepam has an elimination half life of about 33 hours in healthy young subjects and healthy elderly controls, ${ }^{5}$ but this is considerably prolonged in elderly inpatients. ${ }^{4}$ Elderly subjects are more sensitive to the effects of benzodiazepines, ${ }^{6}$ and daytime sedation commonly occurs in elderly inpatients who are prescribed hypnotics with long half lives such as nitrazepam ${ }^{7}$ and flurazepam. ${ }^{8}$

Regular dosing with drugs such as temazepam might be expected to lead to less accumulation and a lower prevalence of daytime sedation than are found with nitrazepam because of their shorter half lives. We therefore studied the hangover effects of temazepam and nitrazepam after the first and seventh of seven daily doses given at night to elderly inpatients to determine whether these differences in half life and predicted accumulation were associated with measurable changes in daytime performance.

Section of Pharmacology, Medical Unit, Royal Free Hospital, London NW3 2QG

PETER J COOK, BSC, MRCP, lecturer in clinical pharmacology

RUTH GRAHAM-POLE, SRN, research assistant

IMOGEN T SAVAGE, BPHARM, MSC, research assistant

IAN M JAMES, PHD, FRCP, senior lecturer in clinical pharmacology

Poisons Unit, New Cross Hospital, London

ANTHONY HUGGETT, BSC, biochemist

\section{Patients and methods}

We used a double-blind trial with randomisation between patients which was balanced for age and mental state. Seventy-one elderly inpatients aged over 65 who were in a stable medical condition and could understand and follow simple instructions were studied. Patients were excluded if they had an acute medical condition-for example, infection or heart failure; had had a stroke within the preceding month or had undergone a surgical procedure within the preceding 10 days; or had received any treatment with benzodiazepines or other sedation for 10 days previously (three weeks for diazepam or flurazepam). Most patients were either recovering from orthopaedic surgery or undergoing rehabilitation after a medical admission.

Informed consent was obtained from all patients, and the study was approved by the hospital ethics committee. Before entry to the study each patient was given a questionnaire to assess mental state (Mill Hill vocabulary score and Raven's progressive matrices ${ }^{9}$ ), which was used to determine the patient's IQ using tables of normal values. ${ }^{10}$ Patients were then allocated to a treatment group using a prerandomised allocation chart. Each patient received seven days' treatment with temazepam $20 \mathrm{mg}$ and placebo nitrazepam, nitrazepam $5 \mathrm{mg}$ and placebo temazepam, or double placebo given at $10 \mathrm{pm}$ each evening. Cerebral blood flow ${ }^{11}$ was estimated.

The patients were assessed on the morning before the first dose (baseline, day 0 ), the morning after the first dose (day 1), and the morning and afternoon after the seventh dose (day 7). They were first asked to rate their previous night's sleep and how alert they felt on a four-part questionnaire. A pair-choice reaction time was then recorded. The patients were instructed to respond to only one of three pairs of coloured lights given in randomised order. A practice run (10 choices, of which four were correct) was always given before the test sequence (10-14 choices, of which six were correct). Single abnormally delayed responses ( mean $+4 \mathrm{SD})$ were excluded. The mean of the five or six correct choices was taken as the mean reaction time. This was followed by a letter E elimination test. The patient was instructed to delete, as quickly as possible, all the e's, of which there were about 150, in a page of unpunctuated prose in large print. A different piece of prose was used on each of the four occasions the test was performed. A worked example and a practice sentence were given before each of the four tests, which were administered in the same order in each patient. The number of errors and the time taken to complete the passage were recorded. All tests were carried out by the same interviewer (RG-P), who was blind to the treatment given. A blood sample was taken on the mornings of days 0,1 , and 7 . Plasma was separated and stored at $-20^{\circ} \mathrm{C}$. Plasma temazepam concentrations were measured by gas-liquid chromatography ${ }^{12}$ and plasma nitrazepam concentrations by high-performance liquid chromatography. ${ }^{13}$

Statistical analysis-The baseline performance of patients varied considerably; this variation exceeded the within-patient differences due to treatment. The results were, therefore, expressed as the changes from the baseline performance. The distribution of the changes in performance and plasma concentrations tended to be skewed, leading to significant changes in variance when tested by the variance ratio (F) test. Statistical analysis of results was therefore carried out using alternative non-parametric tests. ${ }^{14}$ One-tailed tests of significance were used for testing differences against placebo; all other tests were two tailed.

\section{Results}

Comparability-Table I gives details of patient comparability among the 58 patients who completed the trial. There were no significant differences in age, sex, weight, mental state, cerebral blood flow, or baseline performance between the groups.

Withdrawals-Thirteen of the 71 patients who entered the trial 
TABLE I-Comparability of groups (values given as means:-SD)

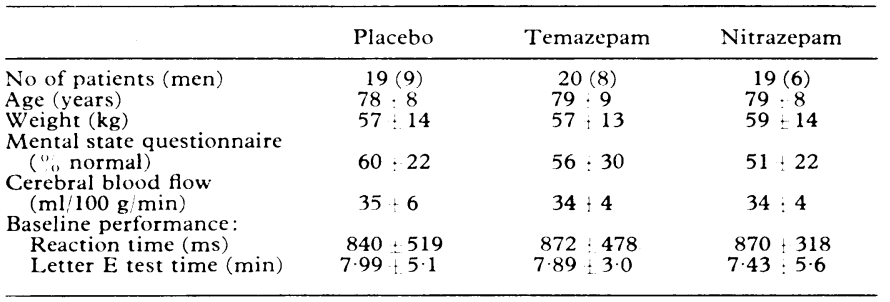

failed to complete it. Five were withdrawn because of poor compliance (two) or intercurrent illness (three), and eight dropped out. Two who dropped out were discharged prematurely and six refused to continue (placebo two, nitrazepam three, temazepam one). Only two patients gave excessive sedation as a reason for stopping (placebo one, nitrazepam one). The initial results in the 13 who did not complete the trial were similar to the results in the 58 who did.

Sleep and alertness questionnaire-Fourteen ( $74 \%$ ) of the 19 patients who received nitrazepam and $13(65 \%)$ of the 20 who received temazepam reported sleeping well (excellent or good) after the first dose compared with six $(32 \%)$ of the 19 patients who received placebo $\left(x^{2}\right.$ test, $\left.p<0 \cdot 05\right)$, but this difference was no longer apparent after the seventh dose (table II). There were no differences in the subjective assessment of alertness.

Choice reaction time (fig 1)-The mean reaction time was unchanged after the first dose of hypnotic but was considerably longer after the seventh dose (Kruskal-Wallis analysis of variance, $p<0.01$ ). This increase in reaction time between day 0 (morning) and day 7 (morning) was significant for temazepam and for nitrazepam when compared with placebo (Mann-Whitney U test : temazepam $v$ placebo, $\mathrm{p}<0.005$; nitrazepam $v$ placebo, $\mathrm{p}<0.05)$. Only some patients in each drug group were affected, some considerably, so that the group response became more variable. A significant increase in variance was found after the

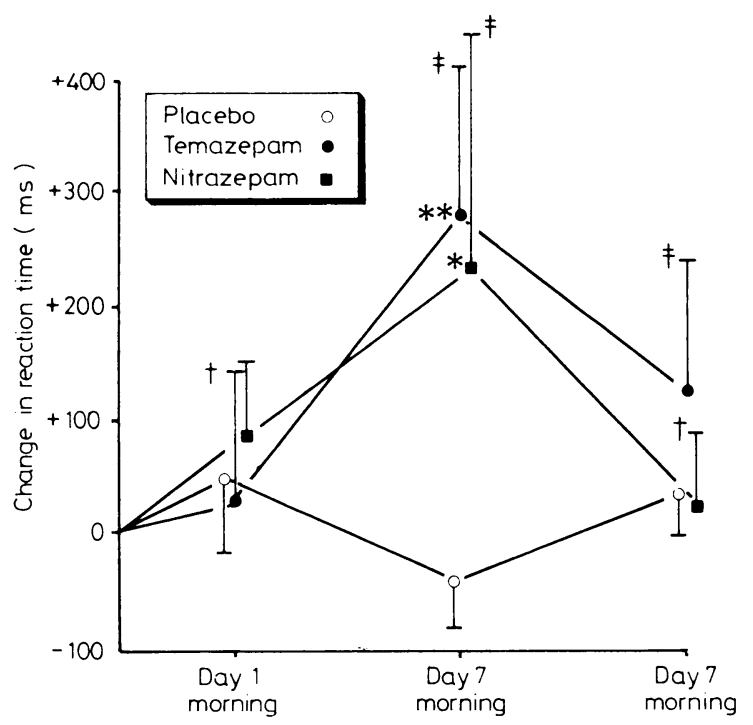

FIG 1 -Change in reaction time (mean $\pm S E)$.

Mann-Whitney U test: ${ }^{*} \mathrm{p}<0.05,{ }^{* *} \mathrm{p}<0.005$. Variance ratio (F) test: $\dagger \mathrm{p}<0.05, \pm \mathrm{p}<0.001$. first dose of temazepam (day 1, morning) and after the seventh dose of both drugs (day 7 , morning and afternoon). The mean reaction tmes and the group variances tended to decrease in the afternoon after the seventh dose.

Letter E elimination (fig 2)-Patients took longer to complete this test on days 1 and 7 compared with day 0 irrespective of treatment. This slowing was more pronounced in those who received hypnotics, but the overall differences did not reach significance on either day (Kruskal-Wallis analysis of variance). The change in time was significant when compared with placebo after the first dose of temazepam (day 1, morning; Mann-Whitney $U$ test, $p<0.05$ ) and after the seventh dose of nitrazepam (day 7, morning; Mann-Whitney $\mathrm{U}$ test, $\mathrm{p}<0.05)$. Patients who received hypnotics tended to make fewer mistakes, so that the overall performances in the test (errors $\times$ time) were not significantly impaired compared with placebo.

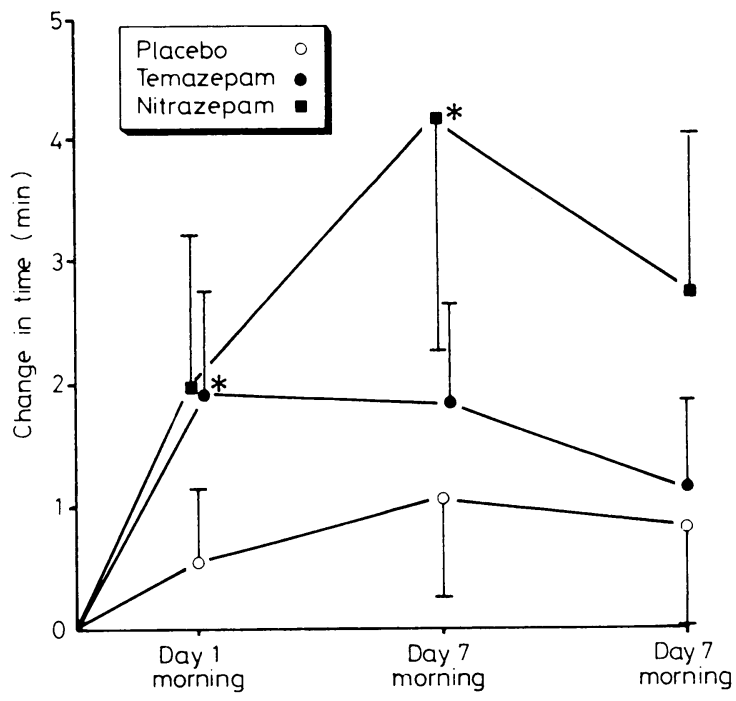

FIG 2-Change in time to complete letter $\mathrm{E}$ test (mean $+\mathrm{SE}$ ). Mann-Whitney U test: ${ }^{*} \mathrm{p}<0 \cdot 05$.

Plasma drug concentrations (fig 3)-Significant plasma accumulation of both drugs occurred during the seven days of dosing (Wilcoxon's signed ranks test, $\mathrm{p}<0.01$, both drugs). The mean morning plasma concentrations of temazepam rose by $50 \%$ from $0.42+$ SD 0.26 $\mu \mathrm{mol} / 1(126 \pm 79 \mathrm{ng} / \mathrm{ml})$ to $0.63 \pm 0.42 \mu \mathrm{mol} / 1(190 \pm 127 \mathrm{ng} / \mathrm{ml})$, and those of nitrazepam rose by $113 \%$ from $0.082 \pm 0.028 \mu \mathrm{mol} / 1(23 \pm 8$ $\mathrm{ng} / \mathrm{ml})$ to $0 \cdot 175 \pm 0.05 \mu \mathrm{mol} / \mathrm{l}(49 \pm 16 \mathrm{ng} / \mathrm{ml})$.

Correlations - There was no correlation between change in performance and age, sex, cerebral blood flow, or plasma drug concentrations. Patients with low IQs who were poor performers tended to be most affected after receiving seven doses of the hypnotics. There was an inverse correlation between IQ and performance that was significant for the time taken to perform the letter E elimination test (Spearman's rank correlation, $\mathrm{r}=-0.46, \mathrm{p}<0.005$ ) but not the choice reaction time.

\section{Discussion}

Studies in elderly inpatients, particularly those with poor comprehension, present particular problems. Such patients are often apprehensive, and the relationship between the patient and

TABLE II-Results of sleep questionnaire (figures are numbers of patients*)

\begin{tabular}{|c|c|c|c|c|c|c|c|c|c|}
\hline & \multicolumn{3}{|c|}{ Day 0} & \multicolumn{3}{|c|}{ Day 1} & \multicolumn{3}{|c|}{ Day 7} \\
\hline & Placebo & Temazepam & Nitrazepam & Placebo & Temazepam & Nitrazepam & Placebo & Temazepam & Nitrazepam \\
\hline $\begin{array}{l}\text { Excellent } \\
\text { Good } \\
\text { Fair } \\
\text { Poor }\end{array}$ & $\begin{array}{r}1 \\
11 \\
6\end{array}$ & $\begin{array}{r}5 \\
11 \\
4\end{array}$ & $\begin{array}{l}5 \\
6 \\
8\end{array}$ & $\begin{array}{r}6 \\
10 \\
3\end{array}$ & $\begin{array}{l}7 \\
6 \\
6 \\
1\end{array}$ & $\begin{array}{l}5 \\
9 \\
2 \\
3\end{array}$ & $\begin{array}{l}1 \\
7 \\
9 \\
2\end{array}$ & $\begin{array}{l}3 \\
7 \\
7 \\
2\end{array}$ & $\begin{array}{l}2 \\
9 \\
4 \\
3\end{array}$ \\
\hline Totals & 18 & 20 & 19 & 19 & 20 & 19 & 19 & 19 & 18 \\
\hline
\end{tabular}

*Some data were incomplete. 
the tester can have a considerable influence on the result. Spontaneous and apparently inexplicable fluctuations in performance were common and led to a large within-subject variation. Ten per cent of the uncorrected reaction times were biased by single greatly prolonged values, which occurred when subjects failed to remember the correct colour combination. This was not a treatment effect since it occurred equally often before and after treatment in the three groups (mainly in mildly demented patients). Simple reaction times might be more reproducible than choice reaction time in such patients. Poor performers also found the letter $\mathrm{E}$ test tiring and tended to lose interest with repeat testing. We subsequently found that administering the test for a shorter fixed period (two minutes) gave more consistent results.

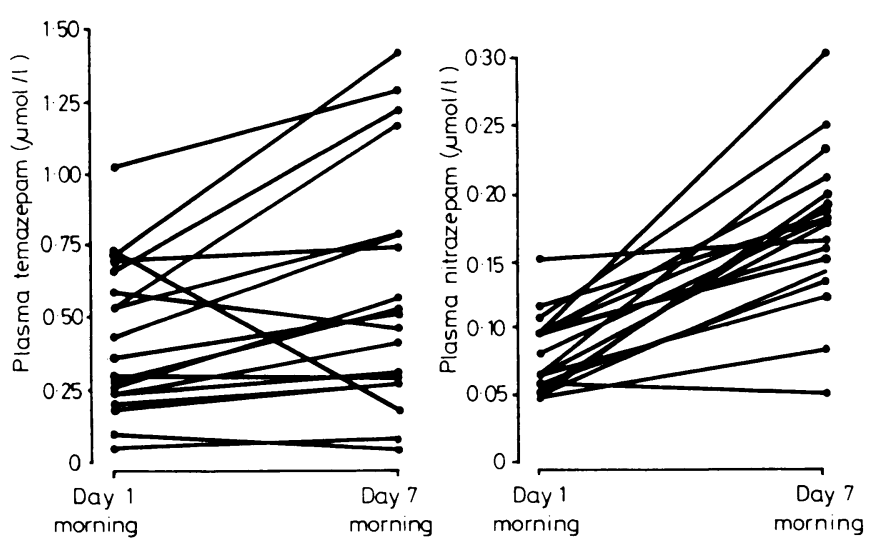

FIG 3-Plasma drug concentrations.

Conversion: SI to traditional units-Temazepam: $1 \mu \mathrm{mol} / 1 \approx 301 \mathrm{ng} / \mathrm{ml}$. Nitrazepam: $1 \mu \mathrm{mol} / 1 \approx 281 \mathrm{ng} / \mathrm{ml}$

Regular dosing with both drugs led to a rise in plasma concentration. This drug accumulation is proportional to the elimination half life and inversely proportional to the dosing interval. ${ }^{15}$ The elimination half lives of temazepam and nitrazepam were estimated from the plasma accumulation ratios and found to be 16 and 26 hours respectively. This compares with published figures of 17 hours for temazepam ${ }^{3}$ and 40 hours for nitrazepam in elderly inpatients. ${ }^{4}$

Previous studies have demonstrated a broad relation in healthy young volunteers between the duration of the effect of a single dose of a hypnotic and its elimination half life. ${ }^{16}{ }^{17}$ Few studies have investigated whether changes in residual effect occur during regular dosing. Considerable accumulation occurs during regular dosing with hypnotics with long elimination half lives such as nitrazepam and flurazepam, ${ }^{18} 19$ yet clinical evidence of sedation appears to be uncommon in young inpatients receiving these drugs. ${ }^{78}$ Clinical impressions may be misleading, and the cumulative adverse effects of high doses of flurazepam $(30 \mathrm{mg}$ ) have been clearly shown in middle-aged people with insomnia. ${ }^{20}$ None the less, the disparity between plasma accumulation and clinical evidence of sedation suggests that appreciable tolerance occurs in the central nervous system of young subjects, which compensates for any increase in effect due to the rise in plasma concentrations. ${ }^{21}$

The results of the present study show that many elderly inpatients show little tolerance during accumulation of the drugs. Surprisingly, the overall effect of the two drugs was similar despite the differences in the degree of accumulation that occurred. Pharmacodynamic differences between drugs may be more important than pharmacokinetic differences. Individual differences in sensitivity are also important. Patients with a low IQ were more likely to show adverse effects. Further multipledose studies are required to confirm these observations and determine which hypnotics are safest for use in elderly subjects.
We thank the pharmacy staff for their help with the study and Wyeth Laboratories Ltd for their generous financial support.

\section{References}

${ }^{1}$ Fucella LM. Bioavailability of temazepam in soft gelatin capsules. $\mathrm{Br} \mathcal{F}$ Clin Pharmacol 1979;8,suppl 1:31-5S.

2 Bittencourt P, Richens A, Toseland PA, Wicks JFC, Latham AN. Pharmokinetics of the hypnotic benzodiazepine, temazepam. Br $\mathcal{F}$ Clin Pharmacol 1979;8,suppl 1:37-8S.

${ }^{3}$ Huggett A, Flanagan RJ, Cook P, Crome P, Corless D. Chlormethiazole and temazepam. Br Med f $1981 ; 282: 475$.

4 Kangas L, Iisalo E, Kanto J, et al. Human pharmacokinetics of nitrazepam: effect of age and diseases. Eur $\mathcal{F}$ Clin Pharmacol 1979;15:163-70.

5 Castledon CM, George CF, Marcer D, Hallett C. Increased sensitivity to nitrazepam in old age. $\mathrm{Br}$ Med $\mathcal{f} 1977 ; \mathrm{i}: 10-2$.

${ }^{6}$ Reidenberg MM, Levy M, Warner $\mathrm{H}$, et al. Relationship between diazepam dose, plasma level, age and CNS depression. Clin Pharmacol Ther $1978 ; 23: 371-4$

${ }^{7}$ Greenblatt DJ, Allen MD. Toxicity of nitrazepam in the elderly: a report from the Boston Collaborative Drug Surveillance Program. Br 7 Clin Pharmacol 1978;5:407-13.

${ }^{8}$ Greenblatt DJ, Allen MD, Shader RI. Toxicity of high dose flurazepam in the elderly. Clin Pharmacol Ther 1977;21:355-61.

${ }^{9}$ Raven JC. Coloured progressive matrices and the Crichton vocabulary scale sets $A, A \mathrm{~B}, B$. London: $\mathrm{H} \mathrm{K}$ Lewis, 1975.

${ }^{10}$ Raven JC, Court JH, Raven J. Manual for Raven's progressive matrices and vocabulary scales. London: $\mathrm{H}$ K Lewis, 1977.

11 Wyper DJ, Lennox GA, Rowan JO. Two minute slope inhalation technique for CBF measurement in man. $\mathcal{f}$ Neurol Neurosurg Psychiatry 1976;39: $141-51$

${ }^{12}$ Belvedere G, Tognoni G, Frigerio A, Morselli PL. A specific, rapid and sensitive method for gas-chromatographic determination of methyloxazepam in small samples of blood. Analytical Letter 1972;5:531-41.

${ }^{13}$ Kelly H, Huggett A, Dawling S. Liquid chromatographic measurement of nitrazepam in plasma. Clin Chem $1982 ; 28: 1478-81$.

${ }^{14}$ Siegal S. Non-parametric statistics for the behavioural sciences. Maidenhead: McGraw-Hill, 1956.

15 Gilbaldi M, Perrier D. Pharmacokinetics. New York: Marcel Dekker, 1975.

${ }^{16}$ Nicholson AN. The use of short- and long-acting hypnotics in clinical medicine. Br $\mathcal{F}$ Clin Pharmacol 1981;11,suppl 1:61-9S.

${ }^{17}$ Roth T, Zorick F, Sicklesteel J, Stepanski E. Effects of benzodiazepines on sleep and wakefulness. Br f Clin Pharmacol 1981;11,suppl 1:31-5S.

${ }^{18}$ Greenblatt DJ, Shader RI, Divoll M, Harmatz JS. Benzodiazepines: a summary of pharmacokinetic properties. Br $\mathcal{F}$ Clin Pharmacol 1981 ;11, suppl 1:11-6S.

19 Greenblatt DJ, Divoll M, Harmatz JS, Machaughlin DS, Shader RI. Kinetics and clinical effects of flurazepam in young and elderly noninsomniacs. Clin Pharmacol Ther $1981 ; 30: 475-86$.

20 Oswald I. The why and how of hypnotic drugs. Br Med 7 1979; : 1167-8.

${ }^{21}$ Hillestad L, Hansen T, Melsom H. Diazepam metabolism in normal man. II. Serum concentrations and clinical effect after oral administration and cumulation. Clin Pharmacol Ther 1974;16:485-9.

(Accepted 28 October 1982)

MEDICINES APPROPRIATED TO THE EARS - The ears are easily afflicted by cold, because they are always open, therefore they require hot medicines. And because they are of themselves very dry, therefore they require medicines which dry much. (Nicholas Culpeper (1616-54) The Complete Herbal, 1850.)

MEDICINES COLD IN THE FOURTH DEGREE-The use of medicines cold in the fourth degree, is, To mitigate desperate and vehement pains, stupifying the senses, when no other course can be taken to save life. (Nicholas Culpeper (1616-54) The Complete Herbal, 1850.)

MEDICINES HOT IN THE THIRD DEGREE-Those which attain the third degree of heat, have the same faculties with those before mentioned; but as they are hotter, so are they more powerful in their operations, for they are so powerful in heating and cutting, that if unadvisedly given they cause fevers. Their use is to cut tough and compacted humours, to provoke sweat abundantly; hence it comes to pass they all of them resist poison. (Nicholas Culpeper (1616-54) The Complete Herbal, 1850.) 